\title{
Food based dietary patterns and chronic disease prevention
}

\author{
Matthias B Schulze and colleagues discuss current knowledge on the associations between \\ dietary patterns and cancer, coronary heart disease, stroke, and type 2 diabetes, focusing on areas \\ of uncertainty and future research directions
}

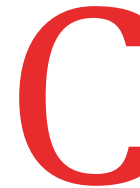

an specific foods provide health benefits? Will adopting a specific food pattern prevent major chronic diseases such as type 2 diabetes, cardiovascular disease, or cancer? Are exclusion diets-vegetarian or vegan diets or avoidance of foods containing gluten, lactose, or fructose-the key to good health? Should doctors advise patients to follow a paleolithic diet? The wide range of popular diet plans and concepts seems to continuously expand. ${ }^{1}$ But to what extent are their purported benefits supported by scientific evidence?

We have qualitatively assessed the available evidence from recent systematic reviews of long term studies to summarise current understanding of foods or dietary patterns and risk of major chronic diseases. Given that nutrition research has been criticised for providing apparently implausible results, ${ }^{23}$ which might contribute to the range of different popular diet concepts, we also discuss methodological approaches and specific challenges of conducting research on food intake patterns and health.

\section{REY MESSAGES}

- Food based prevention of chronic disease risk should prioritise fruits, vegetables, whole grains and fish and lower consumption of red and processed meats and sugar sweetened drinks

- Higher consumption of nuts, legumes, vegetable oils, fermented dairy products, and coffee are further likely to confer benefit

- Evidence comes from prospective observational and intervention studies, each study design having different strengths and limitations. Both types of studies should contribute to the evidence base

- New analytical approaches are needed for nutrition research; eg, to account for measurement error, standardisation of exposure definitions, replication efforts, and the use of repeated dietary assessments
Evaluation of food patterns in nutrition studies Given the relative stability of caloric intake by individual people, changes in dietary habits are generally characterised by substitution effects, where high consumption of some foods is associated with lower intake of other foods. This makes inferences about individual foods particularly challenging. For this reason, researchers also study food patterns, which account for inter-relations of food choices, represent the cumulative exposure to different diet components, and may have stronger effects on health than any single component. ${ }^{4}$

Food patterns can be defined as the quantities, proportions, variety, or combination of different foods and drinks in diets, and the frequency with which they are habitually consumed. ${ }^{5}$ Given that food intake is a multi-dimensional exposure, there are obviously numerous different combinations of foods to potentially investigate. How these combinations are defined in nutrition research largely depends on the research question and study design. In intervention studies food intake is directly manipulated, but in observational studies exposure to food patterns is derived from self reported intake. Two main research methods have been used in this context. ${ }^{46}$ The first is using a priori defined indices intended to capture specific dietary patterns, such as measuring conformity to dietary guidelines. The second is using data driven (exploratory) statistical methods (predominantly cluster analysis, ${ }^{7}$ principal component and factor analysis, ${ }^{48}$ and reduced rank regression ${ }^{69}$ ) to characterise major patterns of food intake. Both approaches allow ranking and quantifying adherence of study participants to these patterns, which is needed to evaluate their association with disease risk. Both approaches and the corresponding statistical methods have their own specific strengths and limitations (table 1).

An evidence based approach can be used to investigate causality between the intake of individual foods or dietary patterns and human health. This approach considers factors such as temporality, consistency, and sources of bias. ${ }^{10}$ The strongest evidence is usually derived from randomised controlled trials because this design minimises confounding bias. But most of the data available come from observational studies on food intake and risk of chronic diseases. Prospective cohort studies have contributed substantially over the past 60 years to what is known today. Systematic reviews have summarised data from such studies and highlighted the importance of individual foods and dietary patterns in the prevention of chronic diseases. ${ }^{11-14}$

\section{Health benefits and risks related to food intake and food patterns}

\section{Individual foods and health outcomes}

Table 2 shows foods and beverages consistently associated in the literature with risk of cancer, type 2 diabetes, coronary heart disease, or stroke. Higher consumption of whole grains is related to lower risk for most endpoints, ${ }^{11-14}$ whereas processed meat and unprocessed red meat consumption is associated with an increased risk. ${ }^{11-14}$ Evidence for other foods is less consistent and might be disease specific- for example, fruits and vegetables are associated with lower risk of cancer,,$^{14}$ coronary heart disease, and stroke, ${ }^{12}{ }^{13}$ but not type 2 diabetes. ${ }^{12}$ The role of dairy foods remains unclear, with fermented dairy products being more convincingly related to lower cardiometabolic disease risk than others ${ }^{1112}$ and total dairy consumption seems relevant to colorectal cancer. ${ }^{14}$ Sugar sweetened drinks are associated with increased risk of type 2 diabetes, ${ }^{11} 12$ coronary heart disease, ${ }^{12}$ ${ }^{13}$ and stroke, ${ }^{13}$ and coffee consumption is associated with lower risk of type 2 diabetes, ${ }^{11}{ }^{12}$ cardiovascular disease, ${ }^{12}{ }^{18}$ and several cancers, ${ }^{1418}$ with beneficial effects being most prominent at consumption of 3-5 cups a day. ${ }^{18}$

\section{Healthy food patterns and health outcomes}

In prospective cohort studies the Mediterranean diet has been associated with lower risk for cancer, type 2 diabetes, and cardiovascular disease. ${ }^{1920}$ Similar findings were reported for the PREDIMED study, a randomised controlled trial of the Mediterranean diet supplemented with extra 
virgin olive oil or nuts (fig 1$).^{2122}$ The primary endpoint of cardiovascular events was about 30\% lower in the intervention groups than in the control group, ${ }^{21}$ and analyses of secondary endpoints support benefits for peripheral artery disease, ${ }^{23}$ atrial fibrillation, ${ }^{24}$ type 2 diabetes, ${ }^{22}$ and breast cancer. ${ }^{25}$ The Mediterranean diet generally refers to a diet encouraging high intake of fruits, nuts and seeds, vegetables, fish, legumes, and cereals and limiting the intake of meat and dairy products. Moderate intake of alcohol and olive oil as a major fat source have also been considered key components. $^{26}$

Several other defined food patterns have been evaluated in terms of chronic disease risk. Indices measuring adherence to the Healthy Eating Index, ${ }^{27}$ Alternative Healthy Eating Index, ${ }^{28}$ and the Dietary Approaches to Stop Hypertension trial $(\mathrm{DASH})^{2930}$ have been associated with lower risk of cardiovascular events, cancer, and type 2 diabetes (fig 2). ${ }^{1931}$ Table 3 shows the composition of these diets in comparison to the Mediterranean diet. Heterogeneity regarding the actual composition of these food scores exists between studies. ${ }^{19}$ Although these diets may be recommendable, only the Mediterranean diet has been shown both in observational studies and a randomised trial to lower disease risk.

Notably, none of the diet plans captures fully the known benefits or detrimental effects of single foods; for example, the Mediterranean diet has traditionally not focused on whole grains or red meat. ${ }^{32}$ Low fat dairy consumption is encouraged in the DASH diet, but discouraged in the Mediterranean diet, although the
Box 1 Limitations of observational nutrition studies on foods and dietary patterns and suggestions for further research

Semiquantitative dietary data

- Use new assessment methods; eg, multiple sources to estimate usual intake

- Evaluate relative versus quantitative scores for dietary patterns and implications of differences in absolute intake levels

Measurement error

- Develop and use measurement error correction methods

- Investigate measurement error influences on dietary pattern composition

- Investigate validity and reliability of dietary patterns

- Develop new biomarkers of food intake and pattern adherence

Correlation of food intake and substitution

- Investigate specific food substitution by statistical modelling

- Investigate influence of energy adjustment in exploratory pattern analysis

Long term variability of intake

- Repeat diet assessments

- Investigate change in intake and subsequent risk

Varying scoring systems for defined food patterns

- Investigate influences of scoring alternatives

- Standardise scoring systems

Population specificity of exploratory patterns

- Replicate pattern associations in independent study populations with varying dietary habits

Different food classification and grouping

- Evaluate influence of food grouping on pattern structure

- Standardise food grouping

Unclear contribution of individual components to pattern association

- Systematically evaluate contribution of each component

evidence for limiting dairy is sparse. ${ }^{29}$ The Mediterranean diet emphasises olive oil, whereas the DASH diet discourages intake of fats and the Alternative Healthy Eating Index refers to high polyunsaturated fatty acid intakes, which would largely reflect vegetable fat sources other than olive oil. Still, these data corroborate previous findings that increased adherence to dietary patterns that emphasise fruits,

Table 1 | Strengths and limitations of approaches to measuring food patterns

\begin{tabular}{|c|c|c|c|}
\hline \multirow[b]{2}{*}{ Defined patterns } & \multicolumn{3}{|c|}{ Exploratory patterns } \\
\hline & Cluster analysis & Principal component and factor analysis & Reduced rank regression \\
\hline \multicolumn{4}{|l|}{ Strengths: } \\
\hline $\begin{array}{l}\text { Information on a variety of food items } \\
\text { can be described by a single score }\end{array}$ & $\begin{array}{l}\text { Information on a variety of food items can } \\
\text { be described by a few mutually exclusive } \\
\text { clusters of people }\end{array}$ & $\begin{array}{l}\text { Information on a variety of food items can be } \\
\text { described by a few underlying uncorrelated } \\
\text { patterns }\end{array}$ & $\begin{array}{l}\text { Information on a variety of food items can be described } \\
\text { by a few underlying uncorrelated patterns }\end{array}$ \\
\hline Easily reproducible and comparable & $\begin{array}{l}\text { Does not require prior theory; based only } \\
\text { on the data }\end{array}$ & $\begin{array}{l}\text { Does not require prior theory; based only } \\
\text { on the data }\end{array}$ & $\begin{array}{l}\text { Combines pathophysiological knowledge (hypothesis } \\
\text { oriented biomarkers) with study data (exploratory } \\
\text { evaluation of food intake) }\end{array}$ \\
\hline $\begin{array}{l}\text { Particularly useful for evaluating } \\
\text { associations between diet and disease } \\
\text { endpoints }\end{array}$ & & $\begin{array}{l}\text { Particularly useful for identifying existing } \\
\text { patterns of food consumption }\end{array}$ & $\begin{array}{l}\text { Particularly useful for identifying patterns related to } \\
\text { disease endpoints }\end{array}$ \\
\hline \multicolumn{4}{|l|}{ Limitations: } \\
\hline $\begin{array}{l}\text { Subjective selection of components } \\
\text { and cut-offs }\end{array}$ & $\begin{array}{l}\text { Subjective decisions regarding cluster } \\
\text { methods, numbers, distance measure }\end{array}$ & $\begin{array}{l}\text { Subjective decisions regarding number of } \\
\text { patterns }\end{array}$ & Subjective decisions regarding number of patterns \\
\hline $\begin{array}{l}\text { Single components are considered as } \\
\text { independent }\end{array}$ & $\begin{array}{l}\text { Descriptive analysis necessary to } \\
\text { characterise patterns }\end{array}$ & $\begin{array}{l}\text { Unclear which food items characterise the } \\
\text { pattern }\end{array}$ & Unclear which food items characterise the pattern \\
\hline $\begin{array}{l}\text { Dependent on strengths of evidence for } \\
\text { hypothesis }\end{array}$ & Procedure not related to outcomes & Procedure not related to outcomes & $\begin{array}{l}\text { Dependent on knowledge and availability of response } \\
\text { variables (eg, disease biomarkers) }\end{array}$ \\
\hline Assumes additive effects & & $\begin{array}{l}\text { Only a low to moderate proportion of intake } \\
\text { explained }\end{array}$ & $\begin{array}{l}\text { Only a low to moderate proportion of response } \\
\text { variation explained }\end{array}$ \\
\hline
\end{tabular}




\section{Box 2 Limitations of randomised controlled trials on food intake and health}

- Recruiting participants for long term changes to diets is difficult, and dropout rates are high

- Dietary advice and actual dietary consumption differ

- Identifying appropriate control diets is challenging, and treatment intensity between intervention and control arms may be imbalanced

- Blinding dietary interventions is frequently unfeasible

- Adherence problems limit the difference in exposure between intervention arms

- Long term interventions to investigate effects on chronic disease risk are costly

vegetables, whole grains, nuts, legumes, vegetable oils, and fish and minimise red meat, processed meat, and added sugars are associated with decreased risk of cardiovascular events, cancer, and type 2 diabetes. $^{5}$

\section{Controversies and research gaps in observational studies}

Evidence for the benefits of fruits, vegetables, whole grains, fish, nuts, legumes, vegetable oils, dairy, coffee, and tea-and for a lower intake of red and processed meats and sugar sweetened drinks- comes largely from observational studies, which have multiple limitations (box 1).

Semiquantitative nature of food intake data in observational studies

Most prospective cohort studies use semiquantitative food frequency questionnaires. These instruments are not designed to provide an accurate estimate of absolute intake. In studies that use quantitative cut-offs to assign points for individual components of the pattern, uncertainty accumulates. Many pattern indices or scores are based on relative cut-offs, which might better reflect the semiquantitative nature of the underlying assessment instrument. ${ }^{4}$ Such approaches usually evaluate intakes relative to the average consumption dose-response relations.

\section{Measurement error} accuracy. level in the studied population; for example, indices to capture exposure to the Mediterranean diet usually assign points for components based on centiles of population intake..$^{42}$ Similarly, pattern scores from principal component or factor analysis are based on food variables standardised to the population mean. Consequently, the average and variation in absolute intake of individual components may vary largely among populations investigated for the same dietary pattern. This is a substantial challenge for making inference on specific

Measurement error is a major limitation of observational nutrition studies. ${ }^{43}$ Researchers have tried to tackle the varying validity and reliability of dietary questionnaires to assess different components of a dietary pattern, ${ }^{44}$ but their results have hardly been used in investigations of dietary patterns and health outcomes. Studies evaluating the validity and reliability of dietary patterns are also scarce. ${ }^{45} 46$ New biomarkers of food intake or food pattern exposure may complement or even substitute traditional dietary assessments. ${ }^{47}$ The use of repeated measurements of food intake over the follow-up period in cohort studies improves

\begin{tabular}{|c|c|c|c|c|}
\hline Food & Cancer & Type 2 diabetes & Coronary heart disease & Stroke \\
\hline Whole grains & $\downarrow 14$ & $\downarrow 1112$ & $\downarrow 1213$ & \\
\hline Vegetables & $\downarrow 14$ & & $\downarrow 1213$ & $\downarrow 1213$ \\
\hline Fruits & $\downarrow 14$ & & $\downarrow 1213$ & $\downarrow 1213$ \\
\hline (Fermented) dairy products & $\downarrow 14$ & $\downarrow 1112$ & & $\downarrow 12$ \\
\hline Red meat & $\downarrow 14$ & $\uparrow 1112$ & $\uparrow 13$ & $\uparrow 1213$ \\
\hline Processed meat & $\downarrow 14$ & $\uparrow 1112$ & $\uparrow 1213$ & $\uparrow 1213$ \\
\hline Fish & & & $\downarrow 1213$ & $\downarrow 1213$ \\
\hline Olive oil & & $\downarrow 15$ & & $\downarrow 16$ \\
\hline Eggs & & $\uparrow 12$ & & \\
\hline Nuts & & $\downarrow 12$ & $\downarrow 1213$ & \\
\hline Cocoa/chocolate & & & $\downarrow 17$ & $\downarrow 17$ \\
\hline Coffee & $\downarrow 1418$ & $\downarrow 111218$ & $\downarrow 1218$ & $\downarrow 1218$ \\
\hline Tea & & $\downarrow 12$ & $\downarrow 12$ & $\downarrow 12$ \\
\hline Sugar sweetened beverages & & $\uparrow 1112$ & $\uparrow 1213$ & $\uparrow 13$ \\
\hline
\end{tabular}

\section{Variation in pattern scoring systems}

Many studies have evaluated a priori defined dietary patterns, but the composition of patterns has varied considerably. ${ }^{19} 2031$ This limitation also applies to randomised trials, where differences in the definition of intervention diets are a major challenge. ${ }^{48}$ Investigations of both single food groups and food patterns are frequently constrained by the information collected in food frequency questionnaires. Although it seems clear that foods with similar characteristics can be put into aggregated groups, broader groups are less homogeneous than narrower ones. The influence of regional foods and of food classifications in the definition and categorisation of food patterns is still understudied. ${ }^{449}$ Comparing different definitions for conceptually similar diets would be an important step forward; for example, Tong and colleagues compared different indices of the Mediterranean diet and cardiovascular disease..$^{50}$

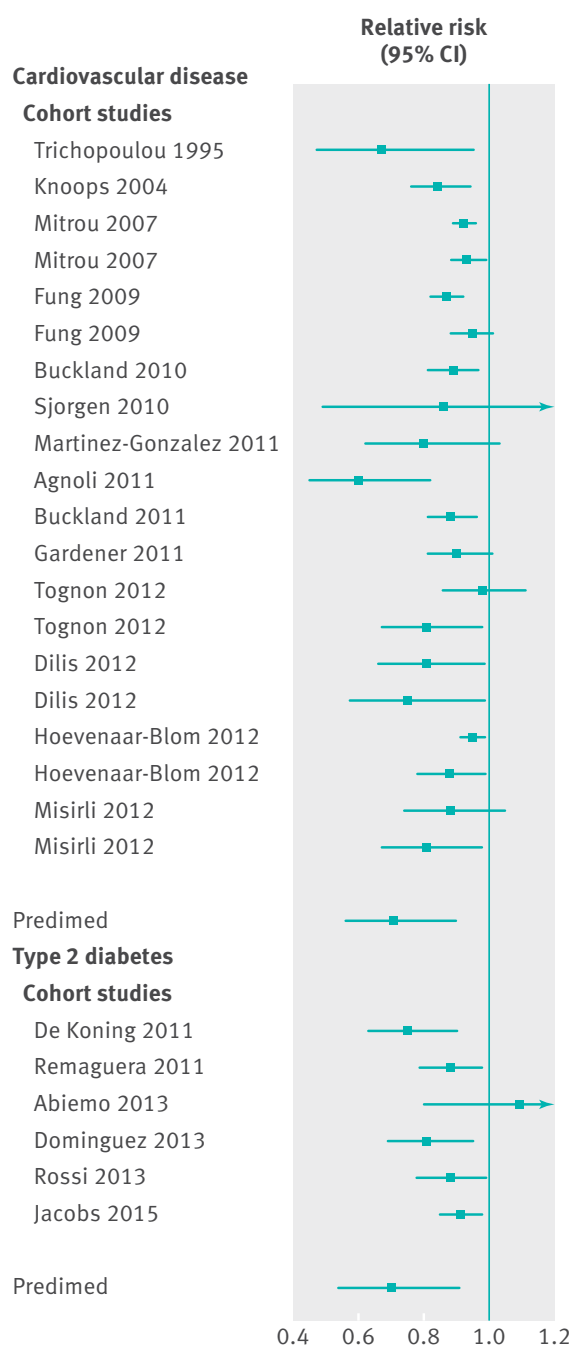

Fig 1 | Mediterranean diet and risk of cardiovascular events and type 2 diabetes in cohort studies according to systematic reviews ${ }^{19} 20$ and the PREDIMED randomised trial. ${ }^{2122}$ 


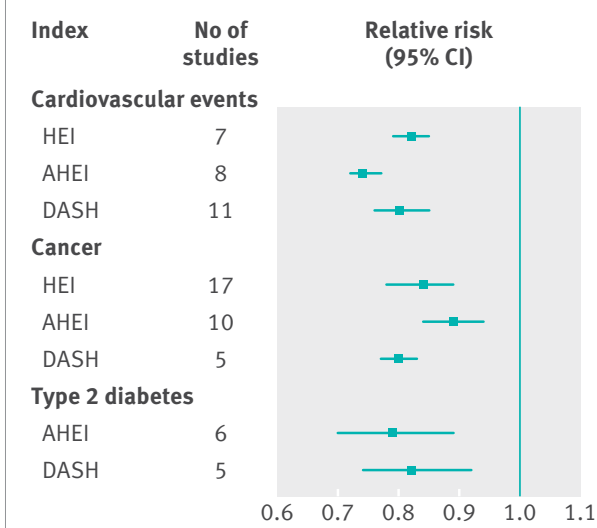

Fig 2 | Dietary patterns and risk of cardiovascular events, ${ }^{31}$ cancer, ${ }^{31}$ and type 2 diabetes ${ }^{19}$ in meta-analyses of prospective cohort studies. AHEI=Alternative Healthy Eating Index; DASH=Dietary Approaches to Stop Hypertension; HEl=Healthy Eating Index.

\section{Food patterns versus individual food components}

Food patterns pre-empt potential dietary confounding by other aspects of the diet, increase the ability to assess stronger effects due to the cumulative effects of many features of the diet, and allow assessment of the interaction among synergistic components. But observed associations could be due to single components rather than the overall dietary pattern. This can be tackled by systematic analysis of the effect of single components for the overall association; for example, the reduced diabetes risk observed for the Mediterranean diet in the Europe-wide EPIC-InterAct study was partly attributable to moderate alcohol, higher olive oil, and lower meat consump- tion. ${ }^{51}$ The evaluation of overall dietary patterns could also mask the effects of individual foods; for example, exploratory patterns including whole grains as components showed only marginal inverse association with diabetes risk, ${ }^{52-57}$ whereas whole grains were inversely associated..$^{58} 59$ Also, dietary patterns usually capture only a fraction of variation in food intake, which leaves a large space of potential effects related to foods not included as components of the pattern.

\section{Generalisability of data driven food patterns}

Exploratory patterns are specific to the population investigated, so the contribution of single study findings to evidence based recommendations is limited. Although exploratory food patterns might have similar components, clear criteria for their consistency needed to summarise observations in meta-analysis are lacking. Replicating study findings in other populations is important, as has been applied in studies using reduced rank regression..$^{60} \mathrm{~A}$ common element of exploratory pattern methods is that investigators must make arbitrary decisions when, for example, selecting the appropriate number of patterns to investigate further (table 1).

\section{Confounding by diet-food substitution}

Observational studies are more prone to confounding bias than randomised controlled trials. Confounding is not only related to other lifestyle factors and general risk factors, but to additional food exposures. Food intake is characterised by combinations and substitutions, so appropriate control of correlated foods is

\begin{tabular}{|c|c|c|c|}
\hline Food & Mediterranean diet ${ }^{2632}$ & DASH $^{2930}$ & Alternative Healthy Eating Index ${ }^{28}$ \\
\hline Cereals* & Encouraged & $\begin{array}{l}\text { Encouraged (whole } \\
\text { grain) }\end{array}$ & Encouraged (whole grain) \\
\hline Vegetables & Encouraged & Encouraged & Encouraged \\
\hline Fruits & Encouraged & Encouraged & Encouraged \\
\hline Nuts, legumes & Encouraged & Encouraged & Encouraged \\
\hline Fish & Encouraged & Encouraged & Encouraged \\
\hline Meatt & Discouraged & Fatty meat discouraged & $\begin{array}{l}\text { Red and processed meat } \\
\text { discouraged }\end{array}$ \\
\hline Dairy products & Discouraged & Encouraged (low fat) & - \\
\hline Fats & Olive oil & Discouraged & $\begin{array}{l}\text { Fat sources high in long chain } \\
\text { omega } 3 \text { and total polyunsaturated } \\
\text { fatty acids, low in trans fatty acids }\end{array}$ \\
\hline $\begin{array}{l}\text { Sweets/sweetened } \\
\text { beverages }\end{array}$ & Discouraged & Discouraged & Discouraged \\
\hline Alcohol & In moderation & - & In moderation \\
\hline Sodium & - & Restricted & Restricted \\
\hline
\end{tabular}

essential in studies investigating individual foods as potential risk factors. Cohort studies provide the possibility to model specific isocaloric food substitutions-an underused approach. When evaluating reductions in red meat intake, for example, taking into account the substitution of other protein sources can be informative. ${ }^{61}$ Pattern analysis might account for intercorrelations among foods.

\section{Timescale of dietary assessment in long term studies}

Inferences from observational studies are usually based on comparisons between different groups that differ in baseline intake; for example, comparing study participants who consume sugar sweetened drinks daily with those who consume them less frequently. Cohort studies can, however, evaluate changes in food consumption if repeated measures of intake are available. Increasing diet quality, assessed as adherence to the Alternative Healthy Eating Index, DASH, or Mediterranean diets, has been found to decrease mortality risk compared with unchanged adherence. ${ }^{62}$ Observational designs that use repeated measurements to assess changes in food patterns can almost simulate interventional trials and provide strong evidence on causality if relevant confounders are controlled.

\section{Potential and limitations of randomised trials}

Randomised controlled trials are less prone to confounding bias and have the ability to control exposure differences between groups, allowing for quantification of dose-response relations. But randomised controlled trials testing dietary interventions are considerably more challenging than standard drug trials (box 2). ${ }^{63}$

One challenge is the difficulty of identifying an appropriate control when evaluating foods or food patterns. ${ }^{64}$ If control participants do not receive a placebo or a comparative intervention, there is strong potential for expectation bias (expected benefit in the intervention group versus expected lack of benefit in the control group). The Women's Health Initiative Dietary Modification Trial, for example, compared a low fat intervention group with intensive behaviour modification counselling to increase fruit, vegetable, and grain consumption with a "usual diet" group receiving diet related education materials only ${ }^{65}$ Although active controls can be designed, such trials are difficult to blind.

Studies depending on dietary advice may not result in sufficiently large differences in food consumption between intervention and control groups due to suboptimal 
compliance of participants-this critique has been raised for large randomised dietary trials, such as the PREDIMED study $^{66}$ and the Women's Health Initiative Dietary Modification Trial. ${ }^{67}$ For large trials with thousands of participants, changing people's habitual dietary patterns demands an unparalleled workload. In addition, the high costs of running long term intervention studies makes it unlikely that associations for multiple foods, food substitutions, and food patterns can be tested for hard outcome endpoints. Still, randomised controlled trials can support or refute observations using surrogate markers of disease. The DASH trial, for example, was a controlled feeding trial with a dietary pattern rich in fruits, vegetables, and low fat dairy products, which reduced blood pressure. ${ }^{29}$ This could be extrapolated to a reduction in cardiovascular event risk, although no randomised trial has been conducted to evaluate if the DASH diet affects incidence of cardiovascular disease. Surrogate (intermediate) markers such as blood pressure can be important mediating factors between food intake, food pattern, and disease risk.

Shorter term randomised trials are not only a tool to support (or refute) the biological causality of observations but can also be used to determine potential effect sizes. But the triangulation of evidence from different sources ${ }^{63}$ might be difficult owing to the different timing and duration of exposures in long term cohort studies versus short term randomised controlled trials of intermediate endpoints, as well as the choice of diet sensitive surrogate markers. ${ }^{68}$ Still, this approach is useful for the popular diet concepts for which evidence on their long term relevance for chronic disease prevention is currently lacking.

Contributors and sources: The author group spans a wide range of expertise from nutritional epidemiology and public health, all of whom have contributed to past dialogue on foods, dietary patterns, and health. Sources of information for this article included published systematic reviews on foods, dietary patterns, and major chronic diseases (coronary heart disease, stroke, type 2 diabetes, and cancer). All authors contributed to drafting this manuscript, with MBS taking a lead role. All authors gave intellectual input to improve the manuscript and have read and approved the final version. MBS is the guarantor.

Competing interests: We have read and understood BMJ policy on declaration of interests and declare the following: MBS receives funding from the German Federal Ministry of Education and Research (FKZ: 01EA1408A-G). MAM-G has no conflict of interest and has received funding from public agencies, including the European Research Council (Advanced Research Grant, \#340918) and from Instituto de Salud Carlos III, CIBEROBN. TTF has nothing to declare. AHL receives funding from the US National Institutes of Health, US Department of Agriculture and the Hass Avocado Board. NGF receives funding from the Medical Research Council Epidemiology Unit (MC_UU_12015/5). She is a member (unpaid) of the
Joint SACN/NHS-England/Diabetes-UK Working Group to review the evidence on lower carbohydrate diets compared with current government advice for adults with type 2 diabetes and is a member (unpaid) of ILSIEurope Qualitative Fat Intake Task Force Expert Group on update on health effects of different saturated fats.

This article is one of a series commissioned by The $B M J$. Open access fees for the series were funded by Swiss Re, which had no input into the commissioning or peer review of the articles.

Matthias B Schulze, professor and department head $^{1,2,}$

Miguel A Martínez-González, professor and department chair ${ }^{4,5,6}$

Teresa T Fung, professor ${ }^{6,7}$

Alice H Lichtenstein, Gershoff professor, director and senior scientist ${ }^{8,9}$

Nita G Forouhi, professor and programme leader ${ }^{10}$

${ }^{1}$ Department of Molecular Epidemiology, German Institute of Human Nutrition Potsdam-Rehbruecke, Nuthetal, Germany.

${ }^{2}$ University of Potsdam, Institute of Nutritional Sciences, Nuthetal, Germany

${ }^{3}$ NutriAct-Competence Cluster Nutrition Research Berlin-Potsdam, Germany

${ }^{4}$ Department of Preventive Medicine and Public Health, University of Navarra-IdiSNA, Pamplona, Spain

${ }^{5}$ CIBER Fisiopatología de la Obesidad y Nutrición (CIBERobn), Instituto de Salud Carlos III (ISCIII), Spain

${ }^{6}$ Department of Nutrition, Harvard TH Chan School of Public Health, Boston, USA

${ }^{7}$ Department of Nutrition, Simmons College, Boston, USA

${ }^{8}$ Friedman School of Nutrition Science and Policy, Tufts University, Boston, USA

${ }^{9}$ Cardiovascular Nutrition Laboratory, Jean Mayer USDA Human Nutrition Research Center on Aging at Tufts University, Boston, USA

${ }^{10}$ Medical Research Council Epidemiology Unit, University of Cambridge, Cambridge, UK

Correspondence to: M B Schulze mschulze@dife.de

US News. Best diets. http://health.usnews.com/bestdiet.

2 loannidis JP. Implausible results in human nutrition research. BMJ 2013;347:f6698. doi:10.1136/bmj. f6698

3 Schoenfeld JD, loannidis JP. Is everything we eat associated with cancer? A systematic cookbook review. Am J Clin Nutr 2013;97:127-34. doi:10.3945/aicn.112.047142

4 Schulze MB, Hoffmann K. Methodological approaches to study dietary patterns in relation to risk of coronary heart disease and stroke. $\mathrm{Br}$ Nutr 2006;95:860-9. doi:10.1079/BJN20061731

5 United States Department of Agriculture. A series of systematic reviews on the relationship between dietary patterns and health outcomes, 2014. https:// www.cnpp.usda.gov/nutrition-evidence-librarydietary-patterns-systematic-review-project.

6 Weikert C, Schulze MB. Evaluating dietary patterns: the role of reduced rank regression. Curr Opin Clin Nutr Metab Care 2016;19:341-6.

7 Devlin UM, McNulty BA, Nugent AP, Gibney M). The use of cluster analysis to derive dietary patterns: methodological considerations, reproducibility, validity and the effect of energy mis-reporting. Proc Nutr Soc 2012:71:599-609. doi:10.1017/ S0029665112000729

8 Gleason PM, Boushey CJ, Harris JE, Zoellner J. Publishing nutrition research: a review of multivariate techniques-part 3: data reduction methods. J Acad Nutr Diet 2015;115:1072-82. doi:10.1016/j. jand.2015.03.011

9 Hoffmann K, Schulze MB, Schienkiewitz A, Nöthlings $\mathrm{U}$, Boeing H. Application of a new statistical method to derive dietary patterns in nutritional epidemiology. Am J Epidemiol 2004;159:935-44. doi:10.1093/ aje/kwh134
10 Hill AB. The environment and disease: association or causation?Proc R Soc Med 1965;58:295-300.

11 Ley SH, Hamdy O, Mohan V, Hu FB. Prevention and management of type 2 diabetes: dietary components and nutritional strategies. Lancet 2014;383:19992007. doi:10.1016/S0140-6736(14)60613-9

12 Mozaffarian D. Dietary and policy priorities for cardiovascular disease diabetes, and obesity: a comprehensive review. Circulation 2016;133:187 225. doi:10.1161/CIRCULATIONAHA.115.018585

13 Bechthold A, Boeing H, Schwedhelm C, et al. Food groups and risk of coronary heart disease, stroke and heart failure: A systematic review and dose-response meta-analysis of prospective studies. Crit Rev Food Sci Nutr 2017. doi:10.1080/10408398.2017.1392 288.

14 World Cancer Research Fund, American Institute for Cancer Research. Diet, nutrition, physical activity and cancer: a global perspective. Continuous Update Project Expert Report 2018. https://www.wcrf.org/ dietandcancer.

15 Schwingshackl L, Lampousi AM, Portillo MP, Romaguera D, Hoffmann G, Boeing H. Olive oil in the prevention and management of type 2 diabetes mellitus: a systematic review and meta-analysis of cohort studies and intervention trials. Nutr Diabetes 2017;7:e262. doi:10.1038/nutd.2017.12

16 Schwingshackl L, Hoffmann G. Monounsaturated fatty acids, olive oil and health status: a systematic review and meta-analysis of cohort studies. Lipids Health Dis 2014;13:154. doi:10.1186/1476-511X-13-154

17 Kwok CS, Boekholdt SM, Lentjes MA, et al. Habitual chocolate consumption and risk of cardiovascular disease among healthy men and women. Heart 2015;101:1279-87. doi:10.1136/ heartjnl-2014-307050

18 Poole R, Kennedy OJ, Roderick P, Fallowfield JA, Hayes PC, Parkes I. Coffee consumption and health umbrella review of meta-analyses of multiple health outcomes. BMJ 2017;359:j5024. doi:10.1136/bmj. j5024

19 Jannasch F, Kröger J, Schulze MB. Dietary patterns and type 2 diabetes: a systematic literature review and meta-analysis of prospective studies. J Nutr 2017;147:1174-82. doi:10.3945/ jn.116.242552

20 Sofi F, Macchi C, Abbate R, Gensini GF, Casini A. Mediterranean diet and health status: an updated meta-analysis and a proposal for a literature-based adherence score. Public Health Nutr 2014:17:276982. doi:10.1017/S1368980013003169

21 Estruch R, Ros E, Salas-Salvadó J, et al, PREDIMED Study Investigators. Primary prevention of cardiovascular disease with a Mediterranean diet. N Engl J Med 2013;368:1279-90. doi:10.1056/ NEJMoa1200303

22 Salas-Salvadó J, Bulló M, Estruch R, et al. Prevention of diabetes with Mediterranean diets: a subgroup analysis of a randomised trial. Ann Intern Med 2014;160:1-10. doi:10.7326/M13-1725

23 Ruiz-Canela M, Estruch R, Corella D, Salas-Salvadó J, Martínez-González MA. Association of Mediterranean diet with peripheral artery disease: the PREDIMED randomised trial. JAMA 2014:311:415-7. doi:10.1001/jama.2013.280618

24 Martínez-González MA, Toledo E, Arós F, et al, PREDIMED Investigators. Extravirgin olive oil consumption reduces risk of atrial fibrillation: the PREDIMED (Prevención con Dieta Mediterránea) trial. Circulation 2014;130:18-26. doi:10.1161/ CIRCULATIONAHA.113.006921

25 Toledo E, Salas-Salvadó J, Donat-Vargas C, et al. Mediterranean diet and invasive breast cancer risk among women at high cardiovascular risk in the PREDIMED trial: a randomised clinical trial. JAMA Intern Med 2015;175:1752-60. doi:10.1001/ jamainternmed.2015.4838

26 Bach-Faig A, Berry EM, Lairon D, et al, Mediterranean Diet Foundation Expert Group. Mediterranean diet pyramid today. Science and cultural updates. Public Health Nutr 2011;14(12A):2274-84. doi:10.1017/ S1368980011002515

27 Guenther PM, Casavale KO, Reedy J, et al. Update of the Healthy Eating Index: HEI-2010. J Acad 
Nutr Diet 2013;113:569-80. doi:10.1016/j. jand.2012.12.016

28 Chiuve SE, Fung TT, Rimm EB, et al. Alternative dietary indices both strongly predict risk of chronic disease. J Nutr 2012;142:1009-18. doi:10.3945/ jn.111.157222

29 Appel LJ, Moore TJ, Obarzanek E, et al, DASH Collaborative Research Group. A clinical trial of the effects of dietary patterns on blood pressure. N Engl J Med 1997;336:1117-24. doi:10.1056/ NEJM199704173361601

30 Fung TT, Chiuve SE, McCullough ML, Rexrode KM, Logroscino G, Hu FB. Adherence to a DASH-style diet and risk of coronary heart disease and stroke in women. Arch Intern Med 2008;168:713-20. doi:10.1001/archinte.168.7.713

31 Schwingshackl L, Hoffmann G. Diet quality as assessed by the Healthy Eating Index, the Alternate Healthy Eating Index, the Dietary Approaches to Stop Hypertension score, and health outcomes: a systematic review and meta-analysis of cohort studies. J Acad Nutr Diet 2015;115:780-800.e5. doi:10.1016/j.jand.2014.12.009

32 Trichopoulou A, Kouris-Blazos A, Wahlqvist $\mathrm{ML}$, et al. Diet and overall survival in elderly people. BMJ 1995;311:1457-60. doi:10.1136/ bmj.311.7018.1457

33 Lee Y, Park K. Adherence to a vegetarian diet and diabetes risk: a systematic review and meta-analysis of observational studies. Nutrients 2017;9:E603. doi:10.3390/nu9060603.

34 Dinu M, Abbate R, Gensini GF, Casini A, Sofi F. Vegetarian, vegan diets and multiple health outcomes: a systematic review with meta-analysis of observational studies. Crit Rev Food Sci Nutr 2017;57:3640-9. doi:10.1080/10408398.20 16.1138447

35 Slimani N, Fahey M, Welch AA, et al. Diversity of dietary patterns observed in the Europea Prospective Investigation into Cancer and Nutrition (EPIC) project. Public Health Nutr 2002;5(6B):131128. doi:10.1079/PHN2002407

36 Satija A, Bhupathiraju SN, Spiegelman D, et al. Healthful and unhealthful plant-based diets and the risk of coronary heart disease in US adults. I Am Coll Cardiol 2017;70:411-22. doi:10.1016/j. jacc.2017.05.047

37 Lebwohl B, Cao Y, Zong G, et al. Long term gluten consumption in adults without celiac disease and risk of coronary heart disease: prospective cohort study. BMJ 2017;357:j1892. doi:10.1136/bmj.j1892

38 Whalen KA, Judd S, McCullough ML, Flanders WD, Hartman TJ, Bostick RM. Paleolithic and mediterranean diet pattern scores are inversely associated with all-cause and cause-specific mortality in adults. J Nutr 2017;147:612-20. doi:10.3945/jn.116.241919

39 Johnston BC, Kanters S, Bandayrel K, et al. Comparison of weight loss among named diet programs in overweight and obese adults: a metaanalysis. JAMA 2014;312:923-33. doi:10.1001/ jama.2014.10397

40 Dansinger ML, Gleason JA, Griffith JL, Selker HP, Schaefer El. Comparison of the Atkins, Ornish, Weight Watchers, and Zone diets for weight loss and heart disease risk reduction: a randomised trial. JAMA 2005;293:43-53. doi:10.1001/ jama.293.1.43

41 Fung TT, Brown LS. Dietary Patterns and the risk of colorectal cancer. Curr Nutr Rep 2013;2:48-55. doi:10.1007/s13668-012-0031-1

42 Trichopoulou A, Martínez-González MA, Tong TY, et al. Definitions and potential health benefits of the Mediterranean diet: views from experts around the world. BMC Med 2014;12:112. doi:10.1186/1741 7015-12-112

43 Sempos CT, Liu K, Ernst ND. Food and nutrient exposures: what to consider when evaluating epidemiologic evidence. $A m$ J Clin Nutr 1999;69:1330S-8S. doi:10.1093/ ajcn/69.6.1330S

44 Zhang S, Midthune D, Guenther PM, et al. A new multivariate measurement error model with zeroinflated dietary data, and its application to dietary assessment. Ann Appl Stat 2011;5(2B):1456-87. doi:10.1214/10-AOAS446

45 Hu FB, Rimm E, Smith-Warner SA, et al. Reproducibility and validity of dietary patterns assessed with a food-frequency questionnaire. Am J Clin Nutr 1999;69:243-9. doi:10.1093/ ajcn/69.2.243

46 Khani BR, Ye W, Terry P, Wolk A. Reproducibility and validity of major dietary patterns among Swedish women assessed with a food-frequency questionnaire. / Nutr 2004:134:1541-5. doi:10.1093/jn/134.6.1541

47 Brennan L, Hu FB. Metabolomics-based dietary biomarkers in nutritional epidemiology-current status and future opportunities. Mol Nutr Food Res 2018;•••:e1701064. doi:10.1002/ mnfr.201701064

48 Grosso G, Mistretta A, Frigiola A, et al. Mediterranean diet and cardiovascular risk factors: a systematic review. Crit Rev Food Sci Nutr 2014;54:593-610. doi :10.1080/10408398.2011.596955

49 Newby PK, Tucker KL. Empirically derived eating patterns using factor or cluster analysis: a review. Nutr Rev 2004:62:177-203. doi:10.1111/j.1753-4887.2004.tb00040.x

50 Tong TY, Wareham NJ, Khaw KT, Imamura F, Forouh NG. Prospective association of the Mediterranean diet with cardiovascular disease incidence and mortality and its population impact in a nonMediterranean population: the EPIC-Norfolk study. BMC Med 2016;14:135. doi:10.1186/s12916-0160677-4

51 Romaguera D, Guevara M, Norat T, et al, InterAct Consortium. Mediterranean diet and type 2 diabetes risk in the European Prospective Investigation into Cancer and Nutrition (EPIC) study: the InterAct project. Diabetes Care 2011;34:1913-8. doi:10.2337/dc11-0891

52 Fung TT, Schulze M, Manson JE, Willett WC, Hu FB. Dietary patterns, meat intake, and the risk of type 2 diabetes in women. Arch Intern Med 2004;164:2235-40. doi:10.1001/ archinte.164.20.2235

53 Bauer F, Beulens JW, van der A DL, et al. Dietary patterns and the risk of type 2 diabetes in overweight and obese individuals. Eur J Nutr 2013;52:1127-34 doi:10.1007/s00394-012-0423-4

54 Malik VS, Fung TT, van Dam RM, Rimm EB, Rosner B, Hu FB. Dietary patterns during adolescence and risk of type 2 diabetes in middle-aged women. Diabetes Care 2012:35:12-8. doi:10.2337/dc11-0386

55 Montonen J, Knekt P, Härkänen T, et al. Dietary patterns and the incidence of type 2 diabetes. Am J Epidemiol 2005;161:219-27. doi:10.1093/aje/ kwi039

56 Nettleton JA, Steffen LM, Ni H, Liu K, Jacobs DR Jr. Dietary patterns and risk of incident type 2 diabetes in the Multi-Ethnic Study of Atherosclerosis (MESA). Diabetes Care 2008;31:1777-82. doi:10.2337/ dc08-0760

57 van Dam RM, Rimm EB, Willett WC, Stampfer MJ, Hu FB. Dietary patterns and risk for type 2 diabetes mellitus in U.S. men. Ann Intern Med 2002;136:201 9. doi:10.7326/0003-4819-136-3-20020205000008

58 de Munter JS, Hu FB, Spiegelman D, Franz M, van Dam RM. Whole grain, bran, and germ intake and risk of type 2 diabetes: a prospective cohort study and systematic review. PLoS Med 2007;4:e261. doi:10.1371/journal.pmed.0040261.

59 Schwingshackl L, Hoffmann G, Lampousi AM, et al. Food groups and risk of type 2 diabetes mellitus: a systematic review and meta-analysis of prospective studies. Eur J Epidemiol 2017;32:363-75. doi:10.1007/s10654-017-0246-y

60 InterAct Consortium. Adherence to predefined dietary patterns and incident type 2 diabetes in European populations: EPIC-InterAct Study. Diabetologia 2014;57:321-33. doi:10.1007| s00125-013-3092-9

61 Pan A, Sun Q, Bernstein AM, et al. Red meat consumption and risk of type 2 diabetes: 3 cohorts of US adults and an updated meta-analysis. Am J Clin Nutr 2011;94:1088-96. doi:10.3945/ ajcn.111.018978

62 Sotos-Prieto M, Bhupathiraju SN, Mattei J, et al. Association of changes in diet quality with total and cause-specific mortality. N Engl / Med 2017;377:143-53. doi:10.1056/ NEJMoa1613502

63 Frieden TR. Evidence for health decision making-beyond randomised, controlled trials. N Engl J Med 2017;377:465-75. doi:10.1056/ NEJMra1614394

64 Staudacher HM, Irving PM, Lomer MCE, Whelan K. The challenges of control groups, placebos and blinding in clinical trials of dietary interventions. Proc Nutr Soc 2017;76:203-12. doi:10.1017/ S0029665117000350

65 Howard BV, Van Horn L, Hsia J, et al. Low-fat dietary pattern and risk of cardiovascular disease: the Women's Health Initiative Randomised Controlled Dietary Modification Trial. JAMA 2006;295:655-66 doi:10.1001/jama.295.6.655

66 Appel LI, Van Horn L. Did the PREDIMED trial test a Mediterranean diet?N Engl / Med 2013;368:1353-4. doi:10.1056/NEJMe1301582

67 Michels KB, Willett WC. The Women's Health Initiative Randomised Controlled Dietary Modification Trial: a post-mortem. Breast Cancer Res Treat 2009;114:1-6 doi:10.1007/s10549-008-9972-x

68 Lawlor DA, Tilling K, Davey Smith G. Triangulation in aetiological epidemiology. Int J Epidemiol 2016;45:1866-86

Cite this as: BMJ 2018;361:j2396

http://dx.doi.org/10.1136/bmj.j2396

\section{OPEN ACCESS}

This is an Open Access article distributed in accordance with the terms of the Creative Commons Attribution (CC BY 4.0) license, which permits others to distribute, remix, adapt and build upon this work, for commercial use, provided the original work is properly cited. See: http:// creativecommons.org/licenses/by/4.0/ 